\title{
BMJ Open Cognitive impairment of workers in a large-scale aluminium factory in China: a cross-sectional study
}

\author{
Huaxing Meng, ${ }^{1,2}$ Shanshan Wang, ${ }^{1}$ Junhong Guo, ${ }^{2}$ Yarong Zhao, ${ }^{2}$ Shuhui Zhang, ${ }^{1}$ \\ Yuqing Zhao, ${ }^{1}$ Qiao Niu ${ }^{1}$
}

To cite: Meng H, Wang S, Guo J, et al. Cognitive impairment of workers in a large-scale aluminium factory in China: a cross-sectional study. BMJ Open 2019;9:e027154. doi:10.1136/ bmjopen-2018-027154

- Prepublication history and additional material for this paper are available online. To view please visit the journal (http:// dx.doi.org/10.1136/bmjopen2018-027154).

Received 11 October 2018 Revised 14 May 2019 Accepted 22 May 2019

\section{Check for updates}

(c) Author(s) (or their employer(s)) 2019. Re-use permitted under CC BY-NC. No commercial re-use. See rights and permissions. Published by BMJ.

${ }^{1}$ School of Public Health, Shanxi Medical University, Taiyuan,

China

${ }^{2}$ Department of Neurology, First Hospital of Shanxi Medical University, Taiyuan, China

Correspondence to

Dr Qiao Niu;

niuqia055@163.com

\section{ABSTRACT}

Objectives To investigate the prevalence of mild cognitive impairment and the relationship with plasma aluminium among aluminium workers.

Design This was a cross-sectional case-control study in the SH Aluminium Factory, China.

Setting The university and affiliated hospital cooperated in the study.

Participants There were 910 aluminium workers on duty, among whom 853 participated in our study. Participants, such as those with cerebral vascular disease, epilepsy, brain trauma, Parkinson's and mental diseases, aluminium-containing drug and mental drug use, and any family history of dementia in first-degree relatives were excluded.

Primary and secondary outcome measures Blood samples were collected, and plasma aluminium was measured by inductively coupled plasma-mass spectrometry. For each case, four age-matched controls were evaluated to determine the relationship between aluminium exposure and mild cognitive impairment. Conditional logistic regression was used to explore influential factors in mild cognitive impairment.

Results Among 910 workers, 93.74\% participated in stage 1; 53 cases were finally diagnosed. The crude prevalence of mild cognitive impairment among aluminium workers on duty was $6.21 \%$. There was a significant difference in plasma aluminium concentration between the two groups. In the multivariate analysis, we found that a higher level of plasma aluminium was associated with a high risk of cognitive impairment when compared with a lower aluminium level $(\mathrm{AOR}=2.24,95 \% \mathrm{Cl}=1.17$ to 4.26), and a high education level was a protective factor ( $\mathrm{AOR}=0.36,95 \% \mathrm{Cl}=0.18$ to 0.70 ). No other factor was statistically significant.

Conclusions Mild cognitive impairment is no longer a disease specific to elderly people. High plasma aluminium exposure might be associated with an increased risk of cognitive impairment, but a reduced risk was observed with a high education level. The cognitive function of aluminium workers on duty must be considered seriously.

\section{INTRODUCTION}

Alzheimer's disease (AD), the most common neurodegenerative disorder in the world, has tremendous consequences for individuals, families and society. ${ }^{12}$ With the increasing

\section{Strengths and limitations of this study}

This investigation was performed using a large sample size.

- This is the first study to evaluate the prevalence of mild cognitive impairment and the relationship with plasma aluminium among aluminium workers on duty in North China.

- Case-control studies were rare among aluminium workers, and neurologists participated in our study.

- This study is limited by its cross-sectional study design, which means our results cannot infer a causal relationship; however, we will continue to observe these workers, and perform a cohort study.

proportion of elderly people, the number of $\mathrm{AD}$ cases will grow by up to threefold by $2050 .^{3} \mathrm{AD}$ is currently considered a continuous disease process that includes mild cognitive impairment (MCI). MCI is the early stage of dementia, ${ }^{4}$ and it is associated with an increased risk of developing dementia. ${ }^{5}$ However, the aetiology of $\mathrm{AD}$ remains unknown after decades of research efforts. The prevalence ratios for black people in different countries clearly vary, indicating that environmental factors may be more important than genetic factors. ${ }^{6}$

Aluminium (Al) is one of the richest elements in the world and is present in every aspect of our life, such as food additives, drugs, cosmetics and industrial production, among others. $\mathrm{Al}$ can enter the body through the skin, digestive tract, muscles and respiratory tract, but it is excreted chiefly through the urine and sweat. ${ }^{7}$ Increasing environmental pollution leads to acid rain, and subsequently the dissolved silicate in the soil enters the water source, ultimately increasing the $\mathrm{Al}$ load in the human body. Al may accumulate in the body after long-term exposure; the skeleton contains approximately 50\% and the lungs $25 \%$ of the body burden. ${ }^{8} \mathrm{Al}^{3+}$ can enter the nervous system through the 
blood-brain barrier (BBB). In addition, relatively direct deposition of $\mathrm{Al}$ from the air to the brain is also possible via the olfactory paths. ${ }^{9}$ Low levels of $\mathrm{Al}$ can lead to behavioural and morphological changes associated with AD. ${ }^{10}$ Since the 1990 s, people have started to pay attention to nervous system damage caused by occupational $\mathrm{Al}$ exposure. Hosovski et $a l^{11}$ and White $e t a l^{12}$ first reported the cognitive decline of $\mathrm{Al}$ foundry workers and smelters. Riihimaki and Aitio ${ }^{13}$ found that cognitive function gradually decreases with the increase in blood Al. A meta-analysis ${ }^{14}$ performed in $449 \mathrm{Al}$-exposed workers in Germany reported the dose-response relationship between $\mathrm{Al}$ and cognitive dysfunction. Other scholars ${ }^{15-18}$ have also reached the same conclusion. In 2014, a case of an occupational $\mathrm{Al}$ worker who progressed to $\mathrm{AD}$ was reported as direct evidence. ${ }^{19}$ Moreover, increased levels of $\mathrm{Al}$ have been reported in the brains of $\mathrm{AD}$ patients and populations with high $\mathrm{Al}$ exposure. ${ }^{20-22}$ Due to the inaccessibility of the human brain, plasma $\mathrm{Al}$ was used herein as the indicator according to previous studies. ${ }^{92} 24$ Compared with the environmental exposure level, it can more accurately reflect the actual $\mathrm{Al}$ exposure of individuals.

Current studies show that the prevalence of MCI or $\mathrm{AD}$ is concentrated in people $>60$ years of age. The MCI prevalence in $\mathrm{Al}$ workers on duty has remained unknown until now. According to statistics from 2013, Al production encompassed close to half of the world, and there were more than 3 million $\mathrm{Al}$ workers in China, providing a good choice for large-sample research. In addition, little work has been conducted on the relationship between MCI and Al. Early detection of MCI and progression prevention are necessary.

The mini-mental state examination (MMSE), which was first introduced by Folstein et $a l^{25}$ in 1975 , has become a standard tool for cognitive assessment. It examines diverse domains: orientation in time and place, memory, language, calculation skills and visuospatial capacity. The clock drawing test (CDT) is the second most widely used screening tool for cognition detection. ${ }^{26}$ Despite appearing simple and easy, it is a complex task that can examine wide scopes of cognition, including planning, executive function, abstract thinking, attention, memory, number order operation, time and space concepts. ${ }^{27}$ In this study, we used MMSE and CDT to evaluate cognition in stage 1 .

We aimed to identify MCI patients and estimate the prevalence of MCI among $\mathrm{Al}$ workers in $\mathrm{SH}$ Aluminium Factory, China. Furthermore, we studied the relationship between plasma $\mathrm{Al}$ and MCI using case-control methods.

\section{MATERIALS AND METHODS \\ Participants and study design}

This study was performed in a large-scale aluminium factory in Hejin, Shanxi Province, North China. Workers on duty in this factory were our target population. Our study was conducted along with the annual health examination in the staff hospital. The workers took work clothes, masks and gloves during working time. The $\mathrm{Al}$ concentration in the drinking water was lower than the national standard $(<0.2 \mathrm{mg} / \mathrm{L})$.

A two-stage survey was designed to evaluate workers with cognitive impairment. In stage 1, trained interviewers (doctors and senior medical students) administered a self-designed questionnaire (online supplementary file ${ }^{28-31}$ for subjects in the $\mathrm{Al}$ factory staff hospital. Intact demographic and medical information was collected to the extent possible, including age, sex, education, marriage, income, employment history, smoking and drinking habits, health situation and drug use. Education was summarised as junior middle school and below ( $\leq 9$ years) and senior middle school and above ( $>9$ years). Marital status, household incomes per capita, employment history and type of work were dichotomised as no or yes, $<1000$ or $\geq 1000$ yuan per month, $<1$ or $\geq 1$ year, and electrolytic or non-electrolytic workers, respectively. Smoking was divided into three categories: never, former and current. Current smokers were defined as subjects who smoke $\geq 1$ cigarette/day for $\geq 6$ months; former smokers were defined as subjects who smoke $<1$ cigarette/day or have quit the habit $\geq 6$ months; subjects who had never smoked were defined as never. Drinking was also divided into three categories: never, former and current. Current drinkers were defined as subjects who drink at least once a week for $\geq 6$ months; former drinkers were defined as subjects who drink less than once a week or have quit the habit for $\geq 6$ months; subjects who had never drunk were defined as never.

After collecting the basic information, the subjects underwent a face-to-face evaluation by the MMSE and CDT scales, both of which were conducted strictly according to the guidelines. The correlation between MMSE and CDT is high, and herein we combined MMSE with $\mathrm{CDT}^{32}{ }^{33}$ to increase the sensitivity and specificity. MMSE (illiteracy $\leq 19$, primary school $\leq 22$, middle school and above $\leq 26$ ) or CDT $\leq 2$ was defined as abnormal. Participants whose MMSE or CDT performances were abnormal or who had complaints of memory impairment entered stage 2.

In stage 2, neurologists from the First Hospital of Shanxi Medical University inquired about the participants' history of cognition. Scales with higher specificity were selected, including the digital span, Fuld objectmemory examination $^{34}$ and rapid verbal retrieve. Cognitive impairment was diagnosed according to the new 2011 National Institute on Aging and Alzheimer's Association (NIA/AA) guidelines. ${ }^{4}$

Exclusion criteria for our study were as follows: (1) any diseases that may cause cognitive impairment including hepatic or renal disorders, brain trauma, cerebrovascular diseases, epilepsy, Parkinson's diseases and mental diseases; (2) any family history of dementia in first-degree relatives; (3) any history of regular drug use (anti-acid drugs containing $\mathrm{Al}$ or mental drugs affecting the central nervous system); (4) use of $\mathrm{Al}$ cookware in the home or daily consumption of vermicelli or fritters; (5) obviously 
poor vision and hearing; (6) workers with missing demographic information and blood samples and (7) dementia defined by impaired daily work and general activity, or poorer life function and execution ability than previously observed, or a condition that could not be explained by delirium or mental illness (as judged by the neurologists).

\section{Ethical statement}

All subjects signed the informed consent.

\section{Biological sample collection and determination of the plasma Al concentration}

Approximately $10 \mathrm{~mL}$ of venous blood was collected from each participant in tubes containing EDTA in blood sampling room of the aluminium factory staff hospital in the early morning. The plasma was separated within $30 \mathrm{~min}$ by centrifugation $\left(4^{\circ} \mathrm{C}, 5 \mathrm{~min}, 1500 \mathrm{rpm}\right)$ into $\mathrm{EP}$ tubes. Before use, the tubes, pipette tips and even the bags containing them were all soaked in acid for 3 days and washed adequately with Milli-Q water. The samples were transported by special delivery to the laboratory and stored at $-80^{\circ} \mathrm{C}$ until analysis.

Plasma $(0.4 \mathrm{~mL})$ was mixed with $1.6 \mathrm{~mL}$ nitric acid $(4 \% \mathrm{v} / \mathrm{v})$ for 24 hours at room temperature and then analysed by inductively coupled plasma mass spectrometry (ICP-MS) (NexlON 300D, PerkinElmer, Waltham, MA, USA) to assess the plasma $\mathrm{Al}$ concentration. EDTA blanks (Milli-Q water) were measured, and the aluminium concentration was below the detection limit $(0.39 \mu \mathrm{g} / \mathrm{L})$. The specimens were measured in random order by blinded laboratory personnel. Each sample was measured twice. We measured blanks and $\mathrm{Al}$ standard liquid (Agilent, Santa Clara, CA, USA) every 10 samples.

In the case-control study, for each case, four controls were matched according to age ( \pm 2 years) in a random manner. The plasma Al concentration was categorised into a binary variable according to the median.

\section{Quality control}

All interviewers were trained strictly by neurologists and psychiatrists. Face-to-face interview and cognitive assessments were performed on the same day. The collection and processing of blood samples was handled by a special personnel.

\section{Statistical analysis}

The database was set up using the software EpiData V.3.1, and the double input method was adopted. All data were analysed using SPSS V.22.0. The concentration of plasma $\mathrm{Al}$ below the limit of detection (LOD) was assigned a value corresponding to one-half the LOD. Outliers were not removed because of their reasonability. The Student's t-test or Mann-Whitney $\mathrm{U}$ test was used to compare continuous variables depending on the distribution types. Differences between categorical variables were calculated using the $\mathrm{X}^{2}$ test. Univariate logistic regression was used to estimate the OR and $95 \%$ CI for cognitive impairment. Multivariate logistic regression was used to analyse all the risk factors. A p value $<0.05$ was considered statistically significant.

\section{Patient and public involvement}

Patients' priorities, experience and preferences were not involved in our study. The diagnosis of MCI was performed according to the NIA/AA guidelines published in 2011. The measurement results were to be disseminated to the participants after the study by the study team and doctors.

\section{RESULTS}

There were 910 workers in SH Aluminium Factory. Of these, $853(93.74 \%)$ participated in stage 1 . They were all men. The mean age and education duration were 44.78 and 10.70 years, respectively. Twenty-two workers were excluded according to the exclusion criteria. Subsequently, $334(39.16 \%)$ workers entered stage 2. In stage 2, $53(6.21 \%)$ workers were finally diagnosed with MCI. Among 53 cases, the chief clinical features were focused on delayed recall $(81.13 \%)$ and visuospatial executive ability $(56.60 \%)$.

For each case, four controls were matched by age $( \pm 2$ years) in a random manner. The characteristics of the cases and controls are presented in table 1 . The mean age of cases and controls were 45.04 and 44.71 years. There were no differences in income, marriage, smoking or drinking between the cases and controls $(p>0.05)$. The MCI cases had a lower education level than the controls $(\mathrm{p}=0.001)$. There was a significant difference in plasma Al between the two groups $(\mathrm{p}=0.001)$. The proportion of $\mathrm{Al}$ working time $\geq 1$ year, plasma $\mathrm{Al} \geq 13.13 \mu \mathrm{g} / \mathrm{L}$ and electrolytic workers were higher among the cases than the controls $(\mathrm{p}=0.005, \mathrm{p}=0.010, \mathrm{p}<0.001)$.

In conditional logistic regression analysis, we found that a higher level of plasma $\mathrm{Al}$ was associated with a high risk of cognitive impairment $(\mathrm{AOR}=2.24,95 \% \mathrm{CI}=1.17$ to 4.26, $\mathrm{p}=0.014$ ), and a high education level was a protective factor (AOR=0.36, 95\% CI=0.18 to 0.70, $\mathrm{p}=0.003$ ). Smoking and drinking were not associated with cognitive impairment in this population ( $p>0.05)$ (table 2).

The combined effect of plasma $\mathrm{Al}$ and education is presented in table 3. Compared with workers with low $\mathrm{Al}$ exposure, those with high $\mathrm{Al}$ exposure and a low education had the highest risk of cognitive impairment. In other words, improving the education level can effectively reduce the risk of cognitive impairment in workers with high $\mathrm{Al}$ exposure $(\mathrm{AOR}=0.36,95 \% \mathrm{CI}=0.19$ to 0.69 , $\mathrm{p}=0.002)$.

\section{DISCUSSION}

Aluminium is widely distributed worldwide, but it is not an essential element for life. Long-term $\mathrm{Al}$ exposure can lead to the accumulation of this metal. ${ }^{835}$ Many studies have indicated that $\mathrm{Al}$ is one of the most important environmental factors in cognitive impairment. ${ }^{36} 37$ 
Table 1 The characteristics of cases and controls

\begin{tabular}{|c|c|c|c|}
\hline Variables & Case $(n=53)$ & Control $(n=212)$ & $P$ value \\
\hline Age, $(m e a n \pm S D)$ & $45.04 \pm 6.15$ & $44.71 \pm 6.11$ & $0.729^{*}$ \\
\hline \multicolumn{4}{|l|}{ Education, n (\%) } \\
\hline Junior middle and below & $34(64.1)$ & $83(39.1)$ & $0.001 \uparrow$ \\
\hline Senior middle and above & $19(35.9)$ & $128(60.9)$ & \\
\hline \multicolumn{4}{|l|}{ Income (RMB) } \\
\hline$<1000$ & $26(51.0)$ & $82(40.4)$ & $0.172 \dagger$ \\
\hline$\geq 1000$ & 25 (49.0) & $121(59.6)$ & \\
\hline \multicolumn{4}{|l|}{ Marriage, n (\%) } \\
\hline No & $0(0)$ & $1(0.5)$ & $0.616 t$ \\
\hline Yes & $53(100)$ & $211(99.5)$ & \\
\hline \multicolumn{4}{|l|}{ Smoking, $\mathrm{n}(\%)$} \\
\hline Never & $23(43.4)$ & $103(48.6)$ & $0.771 \dagger$ \\
\hline Former & $2(3.8)$ & $6(2.8)$ & \\
\hline Current & $28(52.8)$ & $103(48.6)$ & \\
\hline \multicolumn{4}{|l|}{ Drinking, $\mathrm{n}(\%)$} \\
\hline Never & $26(49.0)$ & $125(59.0)$ & $0.424 \dagger$ \\
\hline Former & $10(18.9)$ & $31(14.6)$ & \\
\hline Current & $17(32.1)$ & $56(26.4)$ & \\
\hline \multicolumn{4}{|l|}{ Al working time, $n(\%)$} \\
\hline$<1$ & $34(64.1)$ & $174(82.1)$ & $0.005 t$ \\
\hline$\geq 1$ & 19 (35.9) & $38(17.9)$ & \\
\hline Plasma Al, Med (25th-75th) & $18.17(10.39,34.96)$ & $12.02(6.35,20.86)$ & $0.001 \neq$ \\
\hline \multicolumn{4}{|l|}{ Plasma Al, n (\%) } \\
\hline$<13.13$ & $18(34.0)$ & $114(53.8)$ & $0.010 \dagger$ \\
\hline$\geq 13.13$ & $35(66.0)$ & $98(46.2)$ & \\
\hline \multicolumn{4}{|l|}{ Type of work, n (\%) } \\
\hline Non-electrolytic worker & $31(58.5)$ & $173(81.6)$ & $<0.001 \uparrow$ \\
\hline Electrolytic worker & $22(41.5)$ & 39 (18.4) & \\
\hline
\end{tabular}

Data were presented as mean \pm SD or $n(\%)$ or Med (25th-75th).

Missing value: case (income: 2) control (education: 1 ; income: 9 ).

The unit for age and Al working time was year; RMB is Chinese money, and the unit is yuan; the unit for plasma $\mathrm{Al}$ was $\mu \mathrm{g} / \mathrm{L}$. ${ }^{*} P$ value determined by ANOVA.

†P value determined by the $X^{2}$ test.

$\ddagger P$ value determined by the Mann-Whitney $U$ test.

MCI is considered to be a transitional stage between normal cognitive ageing and $\mathrm{AD} .{ }^{38}$ Effective intervention during the MCI phase can prevent progression. ${ }^{39}$ Our previous population study ${ }^{40}$ showed that retired $\mathrm{Al}$ workers had higher plasma $\mathrm{Al}$ concentrations and a decline in cognitive functions. Moreover, the detection rate of MCI in retired $\mathrm{Al}$ workers was three times greater than the control (18.2\% vs 5.7\%). Thus, $\mathrm{Al}$ workers represent a special group at high risk of developing cognitive decline. There were some limitations to the study. For example, only MMSE was used for retired workers, and the sample size was small. However, $\mathrm{Al}$ toxicity was present before the workers retired. There has been a lack of studies with a large sample size and with data regarding the prevalence of MCI in $\mathrm{Al}$ workers on duty.

There are great challenges for the diagnosis of MCI in epidemiological investigations. The prevalence of MCI among the elderly varies in a wide range from approximately $4.3 \%$ to $36.8 \% .^{541}$ To a large extent, clinician judgement is necessary. In our cross-sectional study, a two-stage design was used to estimate the prevalence of MCI in the SH Aluminium Factory. MCI can affect a variety of cognitive functions, including memory, language, attention and visuospatial executive abilities, and it is often accompanied by memory impairments. An increasing number of studies have shown that visuospatial executive ability 
Table 2 Univariate and multivariate logistic regression analyses of cognitive impairment and plasma Al

\begin{tabular}{|c|c|c|c|c|}
\hline \multirow[b]{2}{*}{ Factors } & \multicolumn{2}{|l|}{ Univariate } & \multicolumn{2}{|l|}{ Multivariate } \\
\hline & OR $(95 \% \mathrm{Cl})$ & $P$ value & AOR $(95 \% \mathrm{Cl})$ & $P$ value \\
\hline \multicolumn{5}{|l|}{ Education } \\
\hline Junior middle and below & 1.0 & & 1.0 & \\
\hline Senior middle and above & 0.37 (0.19 to 0.69$)$ & 0.002 & 0.36 (0.18 to 0.70$)$ & 0.003 \\
\hline \multicolumn{5}{|l|}{ Smoking } \\
\hline Never & 1.0 & & 1.0 & \\
\hline Former & 1.50 (0.29 to 7.79$)$ & 0.627 & 0.97 (0.17 to 5.60$)$ & 0.975 \\
\hline Current & 1.22 (0.66 to 2.25$)$ & 0.526 & 1.15 (0.60 to 2.21$)$ & 0.668 \\
\hline \multicolumn{5}{|l|}{ Drinking } \\
\hline Never & 1.0 & & 1.0 & \\
\hline Former & 1.59 (0.69 to 3.70$)$ & 0.278 & 1.67 (0.68 to 4.11$)$ & 0.266 \\
\hline Current & $1.49(0.74$ to 2.97$)$ & 0.262 & 1.33 (0.63 to 2.81$)$ & 0.451 \\
\hline \multicolumn{5}{|l|}{ Plasma Al } \\
\hline$<13.13$ & 1.0 & & 1.0 & \\
\hline$\geq 13.13$ & 2.21 (1.19 to 4.13$)$ & 0.013 & 2.24 (1.17 to 4.26$)$ & 0.014 \\
\hline
\end{tabular}

The cut-off for the plasma Al was the median. ORs were adjusted for education, smoking and drinking.

The unit for plasma Al was $\mu \mathrm{g} / \mathrm{L}$.

AOR, adjusted odds ratio.

impairment occurs in early stages, even before declarative memory impairment. ${ }^{42}{ }^{43}$ MMSE has a wide range of cognitive domains. CDT is commonly used to reflect the function of the parietal lobe, which is closely related to visual space. ${ }^{445}$ In stage 1 , we combined the MMSE with CDT to detect probable MCI patients to avoid missing cases. In stage 2, neurologists adopted the highly specific questionnaire to improve the accuracy of the diagnosis. Finally, 53 cases were ascertained as contracting MCI, thus generating a crude prevalence rate of $6.21 \%$. This rate was higher than the $1 \%$ reported among people aged $60-64$ years. ${ }^{46}$ Investigations concerning the prevalence of MCI are usually conducted among the elderly, and occupational workers may be ignored. The mean age of the cases was much younger than the general MCI population. Thus, cognitive function may be damaged by $\mathrm{Al}$ in young people.

Among the cases, delayed recall and visuospatial executive abilities were prominently impaired. Many studies have described a decline in memory. In Polizzi et al s study, a negative relationship was observed between serum Al levels and MMSE and CDT scores. ${ }^{17}$ More than half of our cases showed a visual space disorder but without complaints. In recent years, imaging examinations have played an important role in the early diagnosis of $\mathrm{AD}^{47}$ Imaging studies on $\mathrm{AD}$ patients have become commonplace, but they remain limited for occupational workers. It is necessary to conduct imaging examinations of occupational workers to identify early patients and further study the types of cognitive impairment and even the processes underlying their development.

Next, an age-matched case-control study was conducted. Our findings showed that income, marriage, smoking and drinking were evenly balanced between the two groups. However, the plasma $\mathrm{Al}$ concentration was higher in the cases than in the controls. A meta analyses ${ }^{48}$ also demonstrated that $\mathrm{Al}$ levels in $\mathrm{AD}$ cases were significantly elevated in the brain, serum and CSF, particularly in the

Table 3 Joint effects of plasma Al and education on cognitive impairment

\begin{tabular}{|c|c|c|c|c|c|}
\hline \multicolumn{2}{|l|}{ Variables } & \multirow[b]{2}{*}{$\mathbf{N}$} & \multirow{2}{*}{$\begin{array}{l}\text { Case }(\%) \\
(n=53)\end{array}$} & \multirow{2}{*}{$\begin{array}{l}\text { Control }(\%) \\
(n=211)\end{array}$} & \multirow[b]{2}{*}{ AOR $(95 \% \mathrm{Cl})$} \\
\hline Plasma Al & Education & & & & \\
\hline Low exposure & Junior middle and below & 54 & $9(17.0)$ & $45(21.3)$ & 1 \\
\hline \multirow[t]{2}{*}{ High exposure } & Junior middle and below & 63 & $25(47.2)$ & 38 (18.0) & 1 \\
\hline & Senior middle and above & 70 & $10(18.8)$ & $60(28.5)$ & 0.36 (0.19 to 0.69$)$ \\
\hline
\end{tabular}

ORs were adjusted for smoking and drinking.

Missing value: low exposure control (senior middle and above: 1).

AOR, adjusted odds ratio. 
serum, which may serve as an early marker of AD. The plasma $\mathrm{Al}$ concentration was much higher in our cases than in the $\mathrm{AD}$ cases assessed in the above study. The general population is primarily exposed to $\mathrm{Al}$ through the consumption of food items, taking in antacids, ingestion of $\mathrm{Al}$ in drinking water and inhalation of ambient air, though the latter two exposure ways are believed as only minor parts. Workers in $\mathrm{Al}$ industries can be occupationally exposed to airborne $\mathrm{Al}$ particulate at concentrations exceeding the general population exposure. ${ }^{49}$ These results support the existing evidence linking chronic aluminium exposure and the development of AD. Some early studies ${ }^{50}{ }^{51}$ did not find an association between $\mathrm{Al}$ and $\mathrm{AD}$, but those studies have severe limitations related to their retrospective design and sole investigation of the occupational history of $\mathrm{AD}$ patients without plasma Al measurements. Our controls also had higher plasma $\mathrm{Al}$ concentrations than the normal range, as they live in the region of the aluminium factory where the air may have been polluted. ICP-MS is a leading technique for elemental trace analysis due to its great sensitivity, speed and accuracy, even at lower LOD levels $(0.39 \mu \mathrm{g} / \mathrm{L}$ for $\mathrm{Al}$ in our study). Contamination can be easily identified, which is important in $\mathrm{Al}$ research. Moreover, in our study, we found that electrolysis workers were prone to cognitive impairment. Electrolysis is the last process in $\mathrm{Al}$ production, where the workers are mainly exposed to aluminium oxide dust, which is more harmful due to a higher bioavailability. ${ }^{52} 53$

In the multivariate analysis, higher plasma $\mathrm{Al}$ was associated with an increased risk of cognitive impairment. Education was found to be a protective factor for MCI, which has been widely accepted. In the case group, $64.1 \%$ had a low education level, suggesting that the risk of cognitive impairment in $\mathrm{Al}$ workers might be improved through continuing education. For $\mathrm{Al}$ workers with high plasma Al levels, the role of education was more prominent. Smoking and drinking were not associated with MCI in our study. The above results indicated that $\mathrm{Al}$ played an important role in the pathogenesis of cognitive impairment. Our animal experiments $^{54-56}$ and other research ${ }^{5758}$ have confirmed this point.

We investigated, for the first time, the crude prevalence of MCI among on-duty Al workers. Moreover, we provided data supporting the relationship between the plasma Al level and cognitive impairment, proposing valuable interventions. There were some limitations to our study. First, our study may not fully assess the temporal relationship between risk factors and cognitive outcome, and a longitudinal follow-up study is needed to clarify this issue. Second, recall bias may occur in the collection of general demographic data, which may exaggerate or minimise the association between exposure and outcome. Third, the number of cases was still limited. Finally, there were no women in the factory, and consequently data for women are lacking.

\section{CONCLUSIONS}

In conclusion, cognitive impairment is no longer a specific disease of elderly people, electrolytic workers may be at more risk. We observed a significant association between the plasma $\mathrm{Al}$ concentration and cognitive impairment in a Chinese aluminium factory population, and the result of our study imply plasma Al concentration is a significant risk. The workers with higher education level may understand more about the impairment of aluminium on health, and more successful protective measures, thus indicating that high education level could decrease the risk in our study. Our findings require confirmation in other regions, but they may have important implications for public health. Given the large sample of $\mathrm{Al}$ workers in China, the cognitive function of $\mathrm{Al}$ workers must be seriously considered.

Acknowledgements We thank Dr Junhong Guo and Yarong Zhao for the supervision and detailed diagnosis. The authors are grateful to all the participants in this study.

Contributors $\mathrm{QN}$ and $\mathrm{HM}$ : study design; $\mathrm{HM}, \mathrm{JG}$ and $\mathrm{YZ}$ : questionnaire training and diagnosis; SSW, SZ and YZ: data input and sorting; HM and SSW: experiment and data analyses; HM: manuscript writing; QN: revision.

Funding This work was supported by key projects of the National Natural Science Foundation of China (81430078 and 81703202).

Competing interests None declared.

Patient consent for publication Not required.

Ethics approval Ethics approval was provided by the Ethics and Human committees of Shanxi Medical University.

Provenance and peer review Not commissioned; externally peer reviewed.

Data sharing statement № additional data are available.

Open access This is an open access article distributed in accordance with the Creative Commons Attribution Non Commercial (CC BY-NC 4.0) license, which permits others to distribute, remix, adapt, build upon this work non-commercially, and license their derivative works on different terms, provided the original work is properly cited, appropriate credit is given, any changes made indicated, and the use is non-commercial. See: http://creativecommons.org/licenses/by-nc/4.0/.

\section{REFERENCES}

1. Anon. 2018 Alzheimer's disease facts and figures. Alzheimer's \& Dementia 2018;14:367-429.

2. Langa KM, Larson EB, Crimmins EM, et al. A Comparison of the Prevalence of Dementia in the United States in 2000 and 2012. JAMA Intern Med 2017;177:51.

3. Prince M, Bryce R, Albanese E, et al. The global prevalence of dementia: a systematic review and metaanalysis. Alzheimers Dement 2013;9:63-75.

4. Herrup K. Commentary on "Recommendations from the National Institute on Aging-Alzheimer's Association workgroups on diagnostic guidelines for Alzheimer's disease." Addressing the challenge of Alzheimer's disease in the 21st century. Alzheimers Dement 2011;7:335-7.

5. Sachdev PS, Lipnicki DM, Kochan NA, et al. The Prevalence of Mild Cognitive Impairment in Diverse Geographical and Ethnocultural Regions: The COSMIC Collaboration. PLoS One 2015;10:e0142388.

6. Hendrie HC, Osuntokun BO, Hall KS, et al. Prevalence of Alzheimer's disease and dementia in two communities: Nigerian Africans and African Americans. Am J Psychiatry 1995;152:1485-92.

7. Minshall C, Nadal J, Exley C. Aluminium in human sweat. J Trace Elem Med Biol 2014;28:87-8.

8. Jakubowski M. Handbook on the Toxicology of Metals. 4th edn, 2015.

9. Kiesswetter E, Schäper M, Buchta M, et al. Longitudinal study on potential neurotoxic effects of aluminium: I. Assessment of exposure and neurobehavioural performance of $\mathrm{Al}$ welders in the train and 
truck construction industry over 4 years. Int Arch Occup Environ Health 2007:81:41-67.

10. Bondy SC. Low levels of aluminum can lead to behavioral and morphological changes associated with Alzheimer's disease and age-related neurodegeneration. Neurotoxicology 2016;52:222-9.

11. Hosovski E, Mastelica Z, Sunderić D, et al. Mental abilities of workers exposed to aluminium. Med Lav 1990;81:119-23.

12. White DM, Longstreth WT, Rosenstock L, et al. Neurologic syndrome in 25 workers from an aluminum smelting plant. Arch Intern Med 1992;152:1443-8.

13. Riihimäki V, Aitio A. Occupational exposure to aluminum and its biomonitoring in perspective. Crit Rev Toxicol 2012;42:827-53.

14. Meyer-Baron M, Schäper M, Knapp G, et al. Occupational aluminum exposure: evidence in support of its neurobehavioral impact. Neurotoxicology 2007;28:1068-78.

15. Zawilla NH, Taha FM, Kishk NA, et al. Occupational exposure to aluminum and its amyloidogenic link with cognitive functions. $J$ Inorg Biochem 2014;139:57-64.

16. Ahmed T. Consequences of Aluminum exposure on higher cognitive functions. Joint International Symposium on Trace Elements in Man and Animals, 2017.

17. Polizzi S, Pira E, Ferrara M, et al. Neurotoxic effects of aluminium among foundry workers and Alzheimer's disease. Neurotoxicology 2002;23:761-74.

18. Giorgianni $C$, Faranda $M$, Brecciaroli R, et al. [Cognitive disorders among welders exposed to aluminum]. G Ital Med Lav Ergon 2003;25:102

19. Exley C, Vickers T. Elevated brain aluminium and early onset Alzheimer's disease in an individual occupationally exposed to aluminium: a case report. J Med Case Rep 2014;8:41.

20. Bhattacharjee S, Zhao Y, Hill JM, et al. Selective accumulation of aluminum in cerebral arteries in Alzheimer's disease (AD). J Inorg Biochem 2013;126:35-7.

21. Exley C, Esiri MM. Severe cerebral congophilic angiopathy coincident with increased brain aluminium in a resident of Camelford, Cornwall, UK. J Neurol Neurosurg Psychiatry 2006;77:877.

22. Mirza A, King A, Troakes C, et al. Aluminium in brain tissue in familial Alzheimer's disease. J Trace Elem Med Biol 2017;40:30-6.

23. De Sole P, Rossi C, Chiarpotto M, et al. Possible relationship between Al/ferritin complex and Alzheimer's disease. Clin Biochem 2013;46:89-93.

24. Buchta $M$, Kiesswetter $E$, Otto $A$, et al. Longitudinal study examining the neurotoxicity of occupational exposure to aluminium-containing welding fumes. Int Arch Occup Environ Health 2003;76:539-48.

25. Folstein MF, Folstein SE, McHugh PR. "Mini-mental state". A practical method for grading the cognitive state of patients for the clinician. J Psychiatr Res 1975;12:189-98.

26. Yamamoto S, Mogi N, Umegaki H, et al. The clock drawing test as a valid screening method for mild cognitive impairment. Dement Geriatr Cogn Disord 2004;18:172-9.

27. Allone C, Lo Buono V, Corallo F, et al. Cognitive impairment in Parkinson's disease, Alzheimer's dementia, and vascular dementia: the role of the clock-drawing test. Psychogeriatrics 2018;18:123-31.

28. Ho RTH, Fong TCT, Hon T, et al. Psychometric validation of Fuld Object Memory Evaluation in older adults with cognitive impairments. Aging Ment Health 2019;23.

29. Mainland BJ, Amodeo S, Shulman KI. Multiple clock drawing scoring systems: simpler is better. Int J Geriatr Psychiatry 2014;29:127-36.

30. Leung JL, Lee GT, Lam YH, et al. The use of the Digit Span Test in screening for cognitive impairment in acute medical inpatients. Int Psychogeriatr 2011;23:1569-74.

31. Wang B, Guo QH, Chen MR, et al. The clinical characteristics of 2,789 consecutive patients in a memory clinic in China. $J$ Clin Neurosci 2011:18:1473-7.

32. Rubínová E, Nikolai T, Marková $\mathrm{H}$, et al. Clock Drawing Test and the diagnosis of amnestic mild cognitive impairment: can more detailed scoring systems do the work? J Clin Exp Neuropsychol 2014;36:1076-83.

33. Jeong HY, Lee JY, Park HK, et al. Clock drawing test to screen for dementia in Parkinsonian patients with low educational backgrounds. Neurology Asia 2016;21:357-65.

34. Fuld PA. Guaranteed Stimulus-Processing in the Evaluation of Memory and Learning. Cortex 1980;16:255-71.
35. Priest ND. The biological behaviour and bioavailability of aluminium in man, with special reference to studies employing aluminium-26 as a tracer: review and study update. J Environ Monit 2004;6:375-403.

36. Savory J, Herman MM, Ghribi O. Mechanisms of aluminum-induced neurodegeneration in animals: Implications for Alzheimer's disease1. Journal of Alzheimer's Disease 2006;10:135-44.

37. Inaneroglu E, Ayaz A. Is aluminum exposure a risk factor for neurological disorders? Journal of Research in Medical Sciences the Official Journal of Isfahan University of Medical Sciences 2018;23:51.

38. Petersen RC, Caracciolo B, Brayne C, et al. Mild cognitive impairment: a concept in evolution. J Intern Med 2014;275:214-28.

39. Janoutová J, Š O, Hosák L, et al. Is Mild Cognitive Impairment a Precursor of Alzheimer's Disease? Short Review. Central European Journal of Public Health 2015;23:365.

40. Lu X, Liang R, Jia Z, et al. Cognitive Disorders and Tau-Protein Expression Among Retired Aluminum Smelting Workers. J Occup Environ Med 2014:56:155-60.

41. Jang IM, Lee K-B, Roh H, et al. Prevalence and Risk Factors of Dementia and $\mathrm{MCl}$ in Community-dwelling Elderly Koreans. Dement Neurocogn Disord 2014;13:121.

42. Murray ME, Graff-Radford NR, Ross OA, et al. Neuropathologically defined subtypes of Alzheimer's disease with distinct clinical characteristics: a retrospective study. Lancet Neurol 2011;10:785-96.

43. Ahmed S, Brennan L, Eppig J, et al. Visuoconstructional impairment in subtypes of mild cognitive impairment. Alzheimer's \& Dementia 2014;10:P568.

44. Tuokko H, Hadjistavropoulos T, Miller JA, et al. The Clock Test: a sensitive measure to differentiate normal elderly from those with Alzheimer disease. J Am Geriatr Soc 1992;40:579-84.

45. Sack AT, Hubl D, Prvulovic D, et al. The experimental combination of rTMS and fMRI reveals the functional relevance of parietal cortex for visuospatial functions. Brain Res Cogn Brain Res 2002;13:85-93.

46. Su X, Shang $L, X u Q$, et al. Prevalence and predictors of mild cognitive impairment in Xi'an: a community-based study among the elders. PLoS One 2014;9:e83217.

47. Lu D, Popuri K, Ding GW, et al. Multimodal and multiscale deep neural networks for the early diagnosis of Alzheimer's Disease using structural MR and FDG-PET images. Scientific Reports 2018;8.

48. Virk SA, Eslick GD. Aluminum Levels in Brain, Serum, and Cerebrospinal Fluid are Higher in Alzheimer's Disease Cases than in Controls: A Series of Meta-Analyses. Journal of Alzheimer's Disease 2015;47:629-38.

49. Niu Q. Overview of the relationship between aluminum exposure and health of human being. Adv Exp Med Biol 2018;1091:1-31.

50. Salib E, Hillier V. A case-control study of Alzheimer's disease and aluminium occupation. Br J Psychiatry 1996;168:244-9.

51. Gun R, Korten A, Jorm A, et al. Occupational risk factors for Alzheimer disease: a case-control study. Alzheimer Dis Assoc Disord 1997:11:21-7.

52. Krewski D, Yokel RA, Nieboer E, et al. Human health risk assessment for aluminium, aluminium oxide, and aluminium hydroxide. $J$ Toxicol Environ Health B Crit Rev 2007:10:1-269.

53. Reis AP, Patinha C, Noack $Y$, et al. Assessing the human health risk for aluminium, zinc and lead in outdoor dusts collected in recreational sites used by children at an industrial area in the western part of the Bassin Minier de Provence, France. J Afr Earth Sci 2014;99:724-34.

54. Zhang H, Yang X, Qin X, et al. Caspase-3 is Involved in AluminumInduced Impairment of Long-Term Potentiation in Rats Through the Akt/GSK-3ß Pathway. Neurotox Res 2016;29:484-94.

55. Zhang $\mathrm{Q}$, Ding $\mathrm{Y}, \mathrm{He} \mathrm{K}$, et al. Exposure to Alumina Nanoparticles in Female Mice During Pregnancy Induces Neurodevelopmental Toxicity in the Offspring. Front Pharmacol 2018:9:253.

56. Xu Y, Zhang H, Pan B, et al. Transcriptome-Wide Identification of Differentially Expressed Genes and Long Non-coding RNAs in Aluminum-Treated Rat Hippocampus. Neurotox Res 2018;34:220-32.

57. Xu L, Zhang W, Liu X, et al. Circulatory Levels of Toxic Metals (Aluminum, Cadmium, Mercury, Lead) in Patients with Alzheimer's Disease: A Quantitative Meta-Analysis and Systematic Review. J Alzheimers Dis 2018;62:361-72.

58. Klotz K, Weistenhöfer W, Neff F, et al. The Health Effects of Aluminum Exposure. Dtsch Arztebl Int 2017;114:653-9. 